\title{
Impact of devolution on the trends of paediatric malaria admissions and mortality in Homa-Bay County, Kenya
}

\section{Kodhiambo $\mathrm{MO}^{1}$, Amugune $\mathrm{BK}^{2}$, Oyugi $\mathrm{JO}^{3}$}

${ }^{1}$ Department of Pharmacy and Complementary/

Alternative Medicine,

Kenyatta University,

P.O. Box 43844-00100,

Nairobi, Kenya

${ }^{2}$ Department of

Pharmaceutical

Chemistry, University of

Nairobi, Kenya

${ }^{3}$ Department of Medical

Microbiology, University

of Nairobi, Kenya

Corresponding author:

Mr. MO Kodhiambo,

Department of Pharmacy

and Complementary/

Alternative Medicine,

Kenyatta University,

P.O. Box 43844-00100,

Nairobi, Kenya. Email:

kodhiambo.maurice@

ku.ac.ke

\section{Abstract}

Background: Malaria is a leading cause of paediatric admissions, morbidity and mortality. Malaria burden is endemic in Homa Bay County in the Lake Region in Kenya. Low social-economic status in Homa Bay County enhances malaria transmission, morbidity and mortality. Paediatric malaria admission and mortality have recently increased in the lake region unlike the rest of Kenya. Literature review did not show studies interrogating health policy correlates of this malaria problem in the region. The policy of the recently devolvement of the government system in Kenya was to bring services closer to the people. Devolved government in which the county governments are now responsible for healthcare delivery may have unique challenges that may influence disease morbidity and mortality.

Objective: The aim of this study was to investigate the impact of devolution on paediatric malaria admission and mortality trends in public health facilities in Homa Bay County.

Methods: This was a retrospective quasi-experimental study in which paediatrics records of 36 months before and 36 months after the devolvement of government were retrieved and analyzed for malaria incidence and deaths. All records of paediatric malaria cases reported in all 164 public health facilities in Homa-Bay County were examined. Data from the sub-County was obtained from the electronic records at the County Hospital. Hard copy data from health facilities in eight sub-Counties was also inspected at the sub-County level. Analysis of the data was accomplished by use of the Interrupted Time Series (ITS). Permission to conduct the study was obtained from the appropriate authorities. Data coding system was used in order to ensure confidentiality.

Results: From January 2013, deaths increased gradually until around the $33^{\text {rd }}$ month when it rose abruptly to nearly 800 then declined to levels below 200 in the $34^{\text {th }}$ month, which was around the time of devolution. This was followed by a period of stability. Admissions had a similar trend.

Conclusions: There was a slight raise in paediatric malaria admissions and in the number of deaths due to malaria morbidity in Homa Bay County after the devolvement of government system in Kenya a factor which could be attributed to teething challenges of devolution. More studies are necessary to assess progress towards universal access to good healthcare services post devolution.

Key words: Devolution, Paediatric malaria, Admissions, Mortality, HomaBay

\section{Introduction}

Malaria is the leading cause of hospital admisions, morbidity and mortality in the endemic regions of Kenyan children aged 5 years and below are the most vulnerable to malaria infection mainly due to underdeveloped immune mechanism. Kenya has four malaria epidemiological zones based on the disease endemicity which is mainly influenced by temperature, altitude, topology and rainfall patterns. Malaria zones in Kenya are categorized as endemic zones such as the Lake Victoria region including Homa Bay County region, seasonal transmission zones such as arid and semi-arid areas in Northern Kenya, epidemic prone areas like the Western highlands and low risk malaria areas including Nairobi County and the Mount Kenya region.

Until 2013 all government activities were centralized in the national government in a provincial system that consisted of eight Provinces. Subsequently the health system in Homa Bay region was under the central government system. Malaria control and prevention programmes were therefore under the Ministry of Health in the National government. 
In 2013 the government system was devolved into 47 counties in which each County came up with its development plan including that of control of infectious disease. Homa-Bay County therefore has a malaria prevention and control programme in its health development plan. The newly devolved system of government which was aimed at taking services closer to the people was put in place in March 2013. But there was a great deal of unpreparedness to appropriately deliver the services at the county level.

The advent of devolution came with its institutional challenges especially in resource allocation and utilization, human resource and management related issues. For example, the public health managers in the county governments have in the recent past complained about the work environment, transition challenges, restricted decision space, resource constrains and job uncertainty among others $[1,2]$. Such constraints could hinder effective and sustainable health delivery system in the counties.

On the other hand, benefits of devolution to the populations are numerous when all the government systems are improved at the grass root level. Easy accessibility to health facilities and job satisfaction of healthcare givers are of great importance in disease transmission, morbidity and mortality.

Objective: The purpose of this study was to investigate the impact of devolution on paediatric malaria admission and mortality trends in public health facilities in Homa Bay County in Kenya's Lake region.

\section{Materials and Methods}

This was a retrospective quasi-experimental study which was conducted from January 2010 until December 2016 in Homa Bay County. The first 36 months were considered the time before devolution and the following 36 months were the period after the devolution. The study involved analysis of county paediatric malaria admission and mortality records. This information was obtained by reviewing the county and sub-county health records. The study population comprised all paediatric malaria case records in all 164 public healthcare facilities in HomaBay County. Health facilities that started operating after 2012 were excluded from the study.

Data was obtained from the electronic records at the Homa-Bay County teaching and referral hospital after authorization by the necessary county authorities. The data so obtained was an aggregate of facility level monthly admission and mortality. For purposes of triangulation, hard copy data from the health facilities were also inspected at the 8 sub-counties.

Data analysis: Data was analyzed by the Interrupted Time Series (ITS) analytic model. This involved plotting monthly figures of paediatric malaria admissions and mortality in against time. This was done for the time frame of from January 2010 to December 2016, with devolution, being the intervention, occurring around the $36^{\text {th }}$ month. The plot was then visually inspected to see if devolution had an impact on the indicators. This design was used to quantitatively scrutinize trends of paediatric malaria admissions and deaths three years prior to and three years after the roll out of devolution of health care services in Kenya.

The model: The time series analysis was done based on the logistic regression model. For ethical considerations, necessary authority to conduct the study was obtained from the appropriate county authorities. Confidentiality was ensured by using a coding system.

\section{Results}

A total of 275,936 malaria related admissions and 10,239 $(37 \%)$ deaths were reported in the county during the study period. Malaria admissions and the related deaths before 2013 (2010, 2011 and 2012) were deaths before devolution while the cases on 2013 and after $(2013,2014$ and 2015) were treated as deaths after devolution (Table 1). The average proportion of deaths by admissions before devolution was $6.4 \%$ compared to $6.9 \%$ after devolution (Table 1).

Table 1: The number of admissions and deaths before and after devolution in Homa Bay health facilities

\begin{tabular}{|c|c|c|c|c|c|}
\hline \multirow[b]{3}{*}{ Year } & \multicolumn{2}{|c|}{ Admissions } & \multicolumn{3}{|c|}{ Deaths } \\
\hline & \multirow[b]{2}{*}{ Mean } & \multirow[b]{2}{*}{ Total } & \multirow[b]{2}{*}{ Mean } & \multirow[b]{2}{*}{ Total } & \multirow[t]{2}{*}{$\begin{array}{l}\text { Death rate } \\
(\%)\end{array}$} \\
\hline & & & & & \\
\hline & & Before & & & \\
\hline 2010 & 90 & 1,084 & 8 & 90 & 8.3 \\
\hline 2011 & 2,903 & 34,835 & 140 & 1,683 & 4.8 \\
\hline 2012 & 3,283 & 39,397 & 204 & 2,442 & 6.2 \\
\hline \multirow[t]{2}{*}{ Total } & 6276 & 75,316 & 352 & 4215 & 19.3 \\
\hline & & After & & & \\
\hline 2013 & 2,847 & 34,167 & 157 & 1,883 & 5.5 \\
\hline 2014 & 2,056 & 24,668 & 183 & 2,190 & 8.9 \\
\hline 2015 & 2,608 & 31,300 & 163 & 1,951 & 6.2 \\
\hline Total & 7,511 & 90,135 & 503 & 6,024 & 206 \\
\hline
\end{tabular}

Inferential data: The data on paediatric malaria admissions and deaths were plotted against time in months (Figure 1). The graph was generated by a logistic regression modelling technique coupled with an interrupted time series analytic model. From month zero, January 2013, the number of deaths increased gradually until around the $33^{\text {rd }}$ month when it rose abruptly to nearly 800 and declined back to below 200 in the $34^{\text {th }}$ month. This abrupt rise was around the $36^{\text {th }}$ month when devolution of health care was implemented. This was then followed by a fairly stable trend of deaths (around 180 per month). Admission data started from near zero at month zero, increased sharply to almost 1000 in month five then fell equally sharply to zero in month 10 . From month 12, admissions rose drastically to above 4000, stabilized around 3800 up to month 40 followed by a gradual decline to month 60 after which a gradual increase was observed again. 

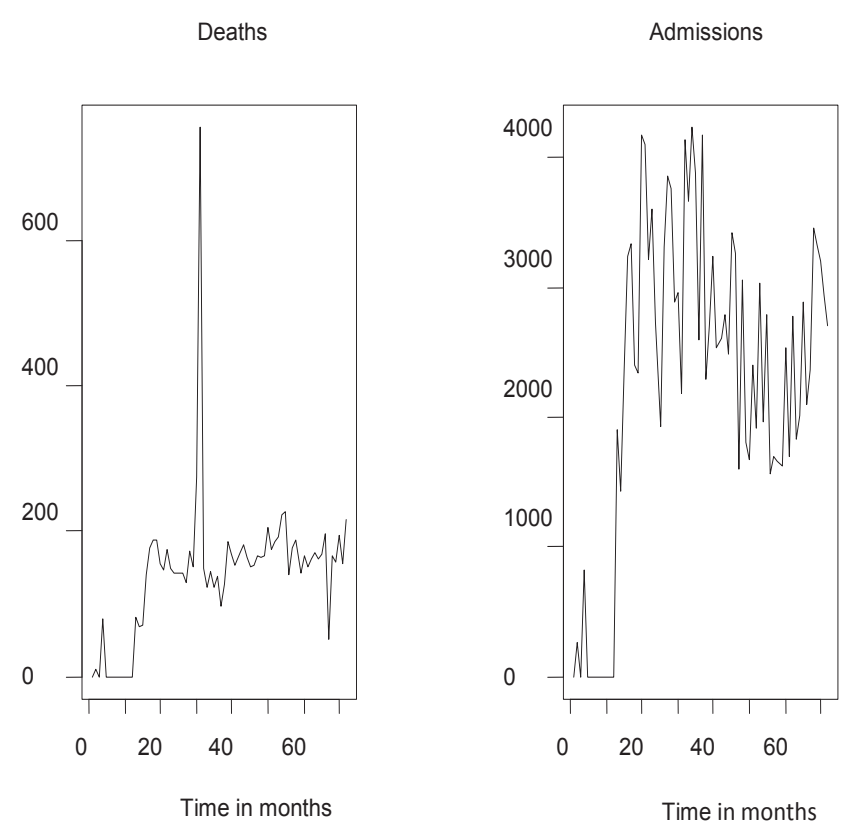

Figure 1: Pattern of paediatric malaria admissions and deaths in Homa Bay County before and after devolution of Government in Kenya

\section{Discussion}

The data after devolution indicated a slight increase in the total number of deaths in relation to the overall malaria admissions in health facilities in Homa Bay County. Admissions increased from 2010 and stabilized around 2013. This was followed by a gradual decline which stabilized again around 2014. The increase in the admissions may be attributed to anticipation of better services given that devolution of other services had begun by 2011. The campaigns to push for decentralization of government system had given people new hopes in relation to improved access healthcare facilities and services and this could have caused a rise in the paediatric malaria admission. Similar observations were made in the residents of Saskatchewan who reported that devolution resulted in greater local control and better quality of healthcare decisions [3] thus a renewed trust in the new system.

There was a slight decline in the number of deaths between 2010 and 2011 and a stabilization phase until 2013 followed by a sharp increase. Mortality was commensurate with the number of admissions. There was a possibility that admissions increased due to better health records management after devolution but this study did not look at the changes in service delivery. On the other hand, the observed changes could have been due to likely changes in the dynamics of transmission of malaria, an area this study did not examine. However, studies conducted elsewhere indicated that most health facilities were not properly prepared to appropriately take up health services at the initial stages of devolved systems [4].

There are scholars who argue that benefits of devolution would accrue mostly to regions where full socio-economic and fiscal power as well as acceptable levels of self health awareness were existing before devolution [4 - 6], unlike the environment in Homa Bay County. Targeted health and civic education may therefore be necessary for communities to realize the full benefits of devolution in healthcare system especially with respect to community participation. Early diagnosis and improved healthcare services coupled by improved levels of self health awareness in the community are vital for a sustained reduction of malaria transmission, morbidity and mortality [7].

In our study, it was clear that the autonomy of the County health care resource management was not adequately prepared to successfully deliver services in a devolved system a factor that could affect early diagnosis and malaria transmission interventions. For example, a lot of money was being used to upgrade the infrastructure of small facilities to higher level hospitals. Such challenges were also experienced earlier in Tanzania [8]. A similar study in Nepal reported poor coordination among different sectors, improper handover process, poor selection of management committees and incoherent capacity building as the other issues that presented as bottlenecks towards early achievement of benefits of devolution [9]. Early diagnosis and improved healthcare services coupled with improved acceptable levels of individual self health awareness in the community are vital for a sustained reduction of malaria transmission, morbidity and mortality [7].

Determinants of disease morbidity are often a complex combination of several interacting factors that may have numerous challenges and may not be effectively studied retrospectively $[10,11]$. At the time of this study, there was poor harmonization of terms of service, human resource incentives and amenities available to health workers in remote areas like Homa Bay County [2]. This could have affected the morale of health care providers, hence poor service delivery leading to an elevation in malaria related deaths in the hospital. A study in Pakistan observed that devolution plans were not often implemented as intended [12]. It is therefore likely that there were deviations in implementation of health care devolution in Kenya, thus leading to unintended outcomes.

\section{Conclusions}

There was a slight raise in paediatric malaria admissions and in the number of deaths due to malaria in Homa Bay County. The study did not look at the factors related to transmission of malaria but the raise in malaria admission could be related to either increased environmental transmission or new challenges in the newly devolved healthcare system. The elevation in the death rates was commensurate with the admission rates but it could also demonstrate the need for improved healthcare delivery system including those related to human resource development and improvement of healthcare delivery facilities. There is a need to conduct a prospective study 
in different counties or to conduct a national survey to take stock of the effects of devolution in paediatric malaria as well as the whole healthcare systems.

\section{References}

1. Nyikuri M, Tsofa B, Barasa E, Okoth $\mathrm{P}$ and Molyneux S. Crises and resilience at the frontlinepublic health facility managers under devolution in a sub-county on the Kenyan Coast. PLoS One. 2015; 10(12): e0144768. doi: 10.1371/journal. pone.0144768. e-Collection 2015.

2. Njuguna J, Mwangi $\mathrm{P}$ and Kamau N. Incentives among health workers in a remote Kenyan district: implications for proposed county health system. $J$ Health Care Poor Underserved. 2014; 25(1):204214. doi: 10.1353/hpu.2014.0029.

3. Lewis SJ, Kouri D, Estabrooks CA, Dickinson H, Dutchak JJ, Williams JI, Mustard C and Hurley J. Devolution to democratic health authorities in Saskatchewan: an interim report. CMAJ. 2001; 164(3):343-347.

4. Jiménez-Rubio $\mathrm{D}$ and García-Gómez P. Decentralization of health care systems and health outcomes: Evidence from a natural experiment. Soc Sci Med. 2017; 188: 69-81. doi: 10.1016/j. socscimed.2017.06.041. Epub 2017 Jul 1.

5. Ramiro LS, Castillo FA, Tan-Torres T, Torres CE, Tayag JG, Talampas RG and Hawken L. Community participation in local health boards in a decentralized setting: cases from the Philippines. Health Policy Plan. 2001; 16 (Suppl 2):61-69.
6. Bossert TJ and Mitchell AD. Health sector decentralization and local decision-making: Decision space, institutional capacities and accountability in Pakistan. Soc Sci Med. 2011; 72(1): 39-48. doi: 10.1016/j.socscimed.2010.10.019. Epub 2010 Nov 11.

7. Okiro EA, Kazembe LN, Kabaria CW, Ligomeka J, Noor AM, Ali D and Snow RW. Childhood malaria admission rates to four hospitals in Malawi between 2000 and 2010. PLoS One. 2013; 8(4): e62214.

8. Kilewo EG and Frumence G. Factors that hinder community participation in developing and implementing comprehensive council health plans in Manyoni District, Tanzania. Glob Health Action. 2015; 8: 26461. doi: 10.3402/gha. v8.26461. e-Collection 2015.

9. Gurung G. Nepal health sector decentralization in limbo: what are the bottlenecks? Nepal Med Coll J. 2011; 13(2):137-139.

10. Doyle Y and Johnstone P. Health benefits from devolution in England: international lessons. Postgrad Med J. 2016; 92(1087):282-285. doi: 10.1136/ postgradmedj-2015-133894. Epub 2016 Feb 23.

11. Lomas J, Woods $\mathrm{J}$ and Veenstra G. Devolving authority for health care in Canada's provinces: 1. An introduction to the issues. CMAJ. 1997; 156(3):371-377.

12. Ansari U, Cockcroft A, Omer K, Ansari NM, Khan A, Chaudhry UU and Andersson N. Devolution and public perceptions and experience of health services in Pakistan: linked cross sectional surveys in 2002 and 2004. BMC Health Serv Res. 2011; 11 (Suppl 2): S4. doi: 10.1186/1472-6963-11-S2-S4. 